\title{
Knowledge on Neonatal Danger Signs and Associated Factors Among Post Natal Mothers in Public Hospitals of Addis Ababa, Ethiopia, 2019. A Cross- Sectional Study Design
}

\section{Wudie Eneyew Ayele ( $\nabla$ wudieeneyew01@gmail.com )}

Debre Markos University

\section{Agegnehu Bantie}

Arbamenchi University

Azene Bantie Wubie

Debre Markos University

Rajalakshmi Murugan

Addis Ababa University

Tewodros Tesfaye

Addis Ababa University

Getaye Worku Tesema

Debre Birhan University

\section{Research Article}

Keywords: Neonatal danger signs, Neonate, Knowledge, Post-natal mothers

Posted Date: February 1st, 2022

DOI: https://doi.org/10.21203/rs.3.rs-1241247/v1

License: (c) (i) This work is licensed under a Creative Commons Attribution 4.0 International License.

Read Full License 


\section{Abstract}

Background: Neonatal danger signs are now a public health problem and contributing factors for neonatal death. Early detection of neonatal danger signs is an important step towards improving newborn survival. This study aimed to assess knowledge on neonatal danger signs and associated factors among post natal mothers in public hospitals of Addis Ababa Ethiopia.

Methods: An institutional based cross-sectional study was conducted among 363 postnatal mothers at public hospitals of Addis Ababa, Ethiopia from March $15^{\text {th }}$ to May $15^{\text {th }}, 2019$. Systematic random sampling technique was used to select the study participants and semi-structure interviewer administer questionnaire was used to collect the data. The data were entered by using Epi- data version 4.4.3.1 and analyzed by using bivariable and multivariable logistic regression model with SPSS version 25.0. Then statistical significance was declared at $\mathrm{P}$ - value $<0.05$. Finally, the data was presented by using text, figures and tables.

Result: All mothers expected to participate in the study were interviewed. Overall, $33.1 \%$ of mothers had good knowledge about neonatal danger signs. Factors like maternal education college and above $(A O R=2.11,95 \% \mathrm{Cl}: 1.51-2.99)$, caesarean section mode of delivery ( $\mathrm{AOR}=3.72,95 \% \mathrm{Cl}: 1.71-8.12)$, parity (AOR=5.34, 95\% Cl: 1.64-2.64), education during PNC follow up ( $\mathrm{AOR}=2.77,95 \% \mathrm{Cl}: 1.49-5.15)$ and identification of skilled birth attendant $(\mathrm{AOR}=2.25,95 \% \mathrm{Cl}: 1.13-4.40)$ were significantly associated with level of maternal knowledge. Similarly, information from health professionals (AOR=4.54, 95\%Cl: 2.169.70) and access to television were also a statistical significant factor for maternal knowledge $(\mathrm{AOR}=2.15,95 \% \mathrm{Cl}: 1.11-4.15)$.

Conclusion: Maternal knowledge on neonatal danger signs was poor. Therefore educational intervention during ante natal care, institution delivery and post natal care visit, advocating the use of media and increase maternal birth preparedness like identification of skilled birth attendant are highly recommended.

\section{Background}

Neonatal danger signs are non-specific signs of severe illness and can be a manifestation of nearly any newborn disease that can be easily identified by non-clinical personnel including the mother. They are clinical signs that would indicate high risk of neonatal morbidity and mortality. Reduction of neonatal mortality relies on early identification of neonatal danger signs by mothers or caregivers $[1,2]$. Neonates" are terms that refer to the first 28 days of life who are more prone to show subtle signs of illness.

Neonatal period is a dangerous time for neonates and high mortality risk. During this period, the highest mortality occurs at the time of birth and decreases over subsequent days and weeks. They often present with non-specific signs and symptoms of severe illness that indicate presence of severe infection which may need immediate care $[6,7]$. 
Up to $36 \%$ of neonatal deaths occur within the first 24 hours of birth and nearly $73 \%$ in the first week of life which needs special attention because most of the health problems are life threatening to them [3-5]. Globally, neonatal mortality is still a significant public health problem [8] which accounts for more than $60 \%$ of new-born deaths before their first birthday [9]. Neonatal danger sign has become a common health problem in many developing countries including Ethiopia. More than $25 \%$ of neonates were born with danger signs [10]. Over 1800 newborns die every day mostly resulted from mothers' failure to identify danger signs of neonates worldwide $[8,9,11]$. Most neonatal deaths $99 \%$ occur in low and middle-income countries and about $50 \%$ of the deaths occur at home due to lack of knowledge towards severe infection signs among mothers or caregivers $[12,13]$.

Almost, $80 \%$ of the world neonatal death, $41 \%$ of death is found in sub-Saharan Africa who has poor knowledge of severe newborn infection signs (danger sings) $[9,14]$. In Nigeria annually more than 0.25 million neonates died and most of the neonates death occur at home without treatment [15]. According to Ethiopian Demographic Health survey (EDHS) 2016, neonatal mortality rates accounts 29 deaths per 1,000 live births and almost half of this death occur due to lack of health seeking behavior of mothers [16]. Neonates with multiple danger signs were more likely to develop multiple complications during the neonatal period and mortality risk may be even higher [10]. Reducing neonatal morbidity and mortality requires mothers or immediate caregiver's recognition of suggestive danger signs and visiting the nearby clinic for early treatment $[17,18]$.

In Ethiopia despite different strategies, intervention programs like integrated management of newborn and childhood illness $(\mathrm{IMNCl})$ and institutional delivery are implemented [12] to reduce danger sign related complication and mortality among neonates, neonatal death due to danger sign is high up to now which needs further study $[10-19,20]$. In Ethiopia nearly all $94 \%$ of neonatal and nationally $42 \%$ of under-five death occurred at home due to the fact that lack of maternal recognition towards neonatal danger signs [20]. The knowledge level on those signs of severe illness has been under studied, resulting in difficulty making progress to reduce neonatal mortality because of delay in seeking care [16]. So, improving maternal knowledge regarding neonatal danger sign is a key entry point for reduction of neonatal mortality [15].

Even though, several studies have examined the determinants of neonatal mortality, limited studies were done on neonatal danger signs and mothers knowledge on it which are potentially cause the morbidity and mortality of neonates. In addition to this, despite neonatal intensive care unit (NICU) is the most important place where most neonates with danger signs are found, there is no any study which includes this unit to assess mothers' knowledge and there is a gap and controversy in assessing mothers' knowledge on neonatal danger signs. Because, most of the researchable studies in Ethiopia, even in foreign countries assessed mother's knowledge based on only one danger sign out of WHO recognized danger signs, with small sample size and the problem of danger signs related death is not reduced still now. 
Moreover, almost all studies assessed maternal knowledge after 28 days (in infant and child stages) which are prone to recall bias and there is no any study conducted on mothers' knowledge towards neonatal danger signs and associated factors in the study area till this time. Therefore, the main aim of this study is to fill the above gaps.

\section{Methods}

\section{Study area, period and design}

An institution based cross-sectional study was conducted in Addis Ababa, the capital city of Ethiopia located at the center of the country. As 2007 Census conducted by the Central Statistical Agency of Ethiopia (CSAE) indicated, Addis Ababa has a total population of 7.8236 million and divided into twelve sub-cities [21] . Currently, the city has twelve governmental and nine private hospitals. Among these, three public hospitals namely, Tikure Anbessa specialized hospital (TASH), Gandhi memorial and St .peter hospitals which are inline of giving NICU service were included in this study. The study was conducted from March15 th to May $15^{\text {th }}, 2019$.

\section{Study population}

All postnatal mothers with their neonates within 28 days (neonatal period) who came to selected public hospitals in Addis Ababa were taken as source population. Postnatal mothers with their neonates within 28 days (neonatal period) who came to selected public hospitals in Addis Ababa and meets inclusion criteria (who were present in the study unit) during the study period were the study populations. Those mothers who had mental health problem, serious illness that makes communication difficult to get the necessary data and who lost their babies were excluded from this study.

\section{Study sampling}

The total sample of the study was determined by using single population proportion formula by assuming $5 \%$ level of significance, $5 \%$ margin of error and by taking $31.3 \%$ proportion of good maternal knowledge on neonatal danger signs [22]. By considering $10 \%$ non-response rate, the final sample size was 363 . Simple random sampling method was used to select study public hospitals and proportional allocation was done for each hospital based on the client flow in the previous months by counting from medical registration book. Then, the study participants were selected by using systematic random sampling method after proportional allocation was done for each selected hospital and all eligible mothers in selected institutions were interviewed.

\section{Operational Definitions}

Knowledge: Understanding of mothers on neonatal danger signs; defined on the basis of their ability to list common neonatal danger signs. A maximum score of knowledge was 14 and a minimum score was 0 . From previous study half and above half $((50 \%)$ and below half $(<50 \%)$ was considered as cut of point. 
Then the mothers were grouped into two based on their score as having good knowledge and poor knowledge.

Good knowledge: Those mothers who got a score of at least 7 from 14 (50\%) neonatal danger signs was considered as having good knowledge.

Poor knowledge: Those mothers who got a score of less than 7 (50\%) questions from 14 neonatal danger sings questionnaire was considered as having poor knowledge.

\section{Data Collection Tools and Procedures}

Semi - structured interviewer administered questionnaire adopted and modified from previous study was employed [23]. The questionnaire was first prepared in English language and then translated to Amharic language. Finally it was retranslated back to English language by experts for its consistency. Seven BSc nurses who were on annual leave as data collectors and three BSc midwifes as supervisors who know and speak both languages were recruited and got training on the objective of the study by the principal investigator. Data collectors explained the purpose of the study to the respondents before data collection based on the training they had got.

\section{Data Quality Control}

The questionnaire was translated into the local language that is Amharic for data collection and then retranslated into English language. The questionnaire was pretested on $5 \%$ of the sample size out of the study area that was not included in the final study at Zewuditu hospital prior to two weeks before actual data collection takes place to ensure its appropriateness. Two days training was given to the data collectors and supervisors on the data collection tool and the data collection procedure. Data collectors were supervised closely by the supervisors and the principal investigator. Completeness of each questionnaire was checked by the principal investigator and the supervisors on daily basis. Double data entry was done by two data clerks and consistency of the entered data was cross checked by comparing the two separately entered data on Epi-Data.

\section{Data collection and analysis}

The completeness and consistency of the data were checked, coded, cleaned and entered by using Epi Data statistical software version 4.4.3.1 and then exported into statistical package for social sciences (SPSS) software version 25.0 for analysis. Descriptive statistical analysis such as simple frequencies, percentage, measures of central tendency and measures of variability were used to describe the characteristics of participants (dependent and independent variables). Binary logistic regression was used to see the association between each independent variable and the outcome variable. The goodness of fit was tested by Hosmer-Lemeshow statistical test. Variables with $p$-value $<0.2$ in the bivariable analysis were entered into multivariable logistic regression mode to control the confounding factors. Multi co-linearity test was carried out to see the correlation between independent variables using collinearity statistics. Adjusted odds ratio (AOR) along with 95\% confidence interval was used to assess 
the strength of the association and $p$-value $<0.05$ was used to declare the level of statistical significance. Finally, the data was presented by using text, tables, graphs and figures.

\section{Results}

\section{Socio- demographic characteristic of the mothers}

A total of 363 mothers were interviewed during data collection with a response rate of $100 \%$; of these, nearly three-fifths $225(62.0 \%$ ) of participants were within 25-34 age group with a mean age of 29.17 (SD $\pm 5.678)$. Almost two third participants $222(61.2 \%)$ were orthodox Christian religion followers and 148 $(40.8 \%)$ of mothers had college and above educational status. Majority of participants, $313(86.2 .0 \%)$ of them were living in urban area. Among the total interviewees, 356 (98.1\%) of them were married (Table 1). 
Table 1

Socio-demographic characteristics of the mother attending health care service at Gandhi, Black lion and St. Peter hospitals from March 15th - May 15th, 2019 ( $N=363)$.

\begin{tabular}{|c|c|c|c|}
\hline Variables & Category & Frequency & Percent \\
\hline \multirow[t]{4}{*}{ Age } & $15-24$ & 68 & 18.7 \\
\hline & $25-34$ & 225 & 62.0 \\
\hline & $35-44$ & 64 & 17.6 \\
\hline & +45 & 6 & 1.7 \\
\hline \multirow[t]{4}{*}{ Religion of mother: } & Orthodox & 222 & 61.2 \\
\hline & Protestant & 72 & 19.8 \\
\hline & Catholic & 11 & 3.0 \\
\hline & Muslim & 58 & 16.0 \\
\hline \multirow[t]{4}{*}{ Educational status of the mother } & Cannot able to read and write & 31 & 8.5 \\
\hline & Grade 1-8 & 67 & 18.5 \\
\hline & Grade 9-12 & 117 & 32.2 \\
\hline & College and above & 148 & 40.8 \\
\hline \multirow[t]{6}{*}{ Occupation of mother: } & House wife & 110 & 30.3 \\
\hline & Merchant & 72 & 19.8 \\
\hline & Government employee & 142 & 39.1 \\
\hline & NGO employee & 20 & 5.5 \\
\hline & Daily laborer & 15 & 4.1 \\
\hline & Other & 4 & 1.1 \\
\hline \multirow[t]{2}{*}{ Mother Place of residence } & Urban & 313 & 86.2 \\
\hline & Rural & 50 & 13.8 \\
\hline \multirow[t]{4}{*}{ Marital status of the mother } & Married & 356 & 98.1 \\
\hline & Divorced & 3 & 0.8 \\
\hline & Widowed & 1 & 0.3 \\
\hline & Single & 3 & 0.8 \\
\hline If married, husband's educational status & Cannot read and write & 19 & 5.3 \\
\hline
\end{tabular}




\begin{tabular}{|c|c|c|c|}
\hline Variables & Category & Frequency & Percent \\
\hline & Grade 1-8 & 75 & 21.1 \\
\hline & Grade 9-12 & 114 & 32.0 \\
\hline & Collage and above & 148 & 41.6 \\
\hline \multirow[t]{5}{*}{ If married, husband's occupation } & Merchant & 76 & 21.3 \\
\hline & Government employee & 127 & 35.7 \\
\hline & Daily laborer & 64 & 18.0 \\
\hline & NGO employee & 50 & 14.0 \\
\hline & Other* & 39 & 11.0 \\
\hline Family size & $1-3$ & 148 & 40.8 \\
\hline \multirow[t]{6}{*}{ Family monthly income } & $4-6$ & 207 & 57.0 \\
\hline & $\geq 7$ & 8 & 2.2 \\
\hline & $601-1650$ & 11 & 3.0 \\
\hline & $1651-3200$ & 63 & 17.4 \\
\hline & $3201-5250$ & 186 & 51.2 \\
\hline & $\geq 5251$ & 103 & 28.4 \\
\hline
\end{tabular}

\section{Maternal health service and obstetric factors}

Among the total participants, 308 (84.4\%) of mothers had ANC follow up at health institution; Out of these, 196 (63.6\%) of mothers had complete ANC follow up. Regarding place of delivery, most of the mothers about 274 (75.5\%) delivered at hospital. In addition to this majority of the interviewees 340 (93.7\%) were assisted by health professionals during their last delivery and most of the interviewees $197(54.3 \%)$ delivered by caesarean section. Majority of the mothers $317(87.3 \%)$ had at least one immediate post natal care follow up. Of these, 165 (52.1\%) of them had three and more than three PNC visit (Table 2). 
Table 2

Maternal health service and obstetric factors among post natal mothers attending health care service at Gandhi, Black lion and St .Peter hospitals from March 15th - May 15th, 2019 (N=363).

\begin{tabular}{|c|c|c|c|}
\hline Variable & Category & Frequency & Percent \\
\hline \multirow[t]{2}{*}{ Did you have ANC follow up? } & No & 55 & 15.2 \\
\hline & Yes & 308 & 84.8 \\
\hline \multirow[t]{2}{*}{ Frequency of ANC visit } & $<4$ & 112 & 36.4 \\
\hline & $\geq 4$ & 196 & 63.6 \\
\hline \multirow[t]{2}{*}{ Where did you give birth } & Health Center & 66 & 18.2 \\
\hline & Hospital & 274 & 75.5 \\
\hline \multirow{3}{*}{$\begin{array}{l}\text { Did you have delivery assistant during the last } \\
\text { delivery? }\end{array}$} & Home & 23 & 6.3 \\
\hline & No & 0 & 0.0 \\
\hline & Yes & 363 & 100 \\
\hline \multirow[t]{5}{*}{ Who gave delivery assistance for you? } & Health professionals & 340 & 93.7 \\
\hline & Family & 6 & 1.7 \\
\hline & Neighbor & 7 & 1.9 \\
\hline & Relatives & 7 & 1.9 \\
\hline & TBA & 3 & 0.8 \\
\hline \multirow[t]{3}{*}{ In which mode of delivery did you give birth? } & $\begin{array}{l}\text { Spontaneous vaginal } \\
\text { delivery }\end{array}$ & 113 & 31.1 \\
\hline & $\begin{array}{l}\text { Instrumental assisted } \\
\text { delivery }\end{array}$ & 53 & 14.6 \\
\hline & Caesarean section & 197 & 54.3 \\
\hline \multirow[t]{3}{*}{ Number of Parity } & 1 & 45 & 12.4 \\
\hline & $2-3$ & 153 & 42.1 \\
\hline & $>3$ & 165 & 45.5 \\
\hline \multirow[t]{2}{*}{ Do have immediate PNC visit? } & No & 46 & 12.7 \\
\hline & Yes & 317 & 87.3 \\
\hline Frequency of PNC visit & $<3$ & 152 & 47.9 \\
\hline \multirow{2}{*}{$\begin{array}{l}\text { Do you know Post Natal Period (PNP) is a danger } \\
\text { time for neonates? }\end{array}$} & $\geq 3$ & 165 & 52.1 \\
\hline & No & 175 & 48.2 \\
\hline
\end{tabular}




\section{Birth preparedness}

Out of the total study participants, most of the mothers $271(74.7 \%)$ had birth preparedness. Of these one hundred seventy five (64.6\%) of mothers prepared financially for their last delivery. Among mothers who had birth preparedness, nearly two-third of the mothers 199 (73.4\%) identified skilled birth attendant and $237(87.5 \%)$ identified health facility for their last delivery (Table 3 ).

Table 3

Birth preparedness among post natal mothers attending health care service at Gandhi, Black lion and St. Peter hospitals from March 15th - May 15th, $2019(\mathrm{~N}=363)$.

\begin{tabular}{|c|c|c|c|}
\hline Variable Category & & Frequency & Percent \\
\hline \multirow[t]{2}{*}{ Birth preparation for the last delivery } & No & 92 & 25.3 \\
\hline & Yes & 271 & 74.7 \\
\hline \multirow[t]{5}{*}{ Type of preparation for delivery } & Financial preparation & 175 & 64.6 \\
\hline & Transport for emergency case & 104 & 38.4 \\
\hline & $\begin{array}{l}\text { Identification of skilled birth } \\
\text { attendant }\end{array}$ & 199 & 73.4 \\
\hline & Identification of health facility & 237 & 87.5 \\
\hline & Other* & 27 & 9.9 \\
\hline \multirow{2}{*}{$\begin{array}{l}\text { Arranged a place for delivery during your } \\
\text { pregnancy }\end{array}$} & No & 114 & 31.4 \\
\hline & Yes & 249 & 68.6 \\
\hline \multirow{3}{*}{ Arranged place for delivery } & Health center & 105 & 42.2 \\
\hline & Hospital & 127 & 51.0 \\
\hline & Home & 17 & 6.8 \\
\hline
\end{tabular}

\section{Source of information about neonatal danger signs and counseling service}

The finding of this study showed that, about 319(87.9\%) of mothers heard about neonatal danger signs. The major sources of information about neonatal danger signs were health care providers $253(69.7 \%)$. In 
addition to this, two hundred nine (57.6\%), $158(43.3 \%), 151(41.6 \%)$ and $48(13.2 \%)$ of participants got information from television, radio, health extension workers and others respectively as shown below in (Figure 1). Of all participants, one hundred ninety one (52.6\%) of mothers had gotten education during PNC visit.

\section{Maternal knowledge on neonatal danger signs}

Among the total participants, three hundred seventeen (87.3\%) of the mothers able to mention at least one neonatal danger signs. The finding of this study showed that, only $120(33.1 \%)$ of mothers had good knowledge as explained with (figure 2) below. The most commonly known neonatal danger signs was fever which is known by two hundred sixty-three $(72.5 \%)$ of mothers whereas the least known neonatal danger sign was very small baby known by $36(9.9 \%)$ of mothers. In addition to this, 239 (65.8\%), 223 (61.4\%) and 204 (56.2\%) of mothers identified poor sucking, persistent vomiting and yellow discoloration respectively (Table 4). 
Table 4

Assessment of knowledge on neonatal danger signs among post natal mothers at Gandhi, Black lion and St. Peter hospitals from March 15th - May 15th, $2019(\mathrm{~N}=363)$.

\begin{tabular}{|c|c|c|c|}
\hline Knowledge assessment Category & & Frequency & Percent \\
\hline \multirow[t]{2}{*}{ Do you know about neonatal danger signs? } & No & 46 & 12.7 \\
\hline & Yes & 317 & 87.3 \\
\hline \multirow[t]{2}{*}{ Poor sucking or not able to breast feed } & No & 124 & 34.2 \\
\hline & Yes & 239 & 65.8 \\
\hline \multirow[t]{3}{*}{ Fever: } & No & 100 & 27.5 \\
\hline & Yes & 263 & 72.5 \\
\hline & Yes & 169 & 46.6 \\
\hline \multirow[t]{2}{*}{ Difficulty of breathing } & No & 255 & 70.2 \\
\hline & Yes & 108 & 29.8 \\
\hline \multirow[t]{2}{*}{ Lethargic/unconscious: } & No & 248 & 68.3 \\
\hline & Yes & 115 & 31.7 \\
\hline \multirow[t]{2}{*}{ Hypothermia: } & No & 299 & 82.4 \\
\hline & Yes & 64 & 17.6 \\
\hline \multirow[t]{2}{*}{ Convulsion } & No & 248 & 68.3 \\
\hline & Yes & 115 & 31.7 \\
\hline \multirow[t]{2}{*}{ Umbilical infection/redness of the cord } & No & 278 & 76.6 \\
\hline & Yes & 85 & 23.4 \\
\hline \multirow[t]{2}{*}{ Yellowish discoloration of yes, palms/soles } & No & 159 & 43.8 \\
\hline & Yes & 204 & 56.2 \\
\hline \multirow[t]{2}{*}{ Persistent vomiting } & No & 140 & 38.6 \\
\hline & Yes & 223 & 61.4 \\
\hline \multirow[t]{2}{*}{ Very small neonate: } & No & 327 & 90.1 \\
\hline & Yes & 36 & 9.9 \\
\hline \multirow[t]{2}{*}{ Pus discharge or redness of eye } & No & 295 & 81.3 \\
\hline & Yes & 68 & 18.7 \\
\hline No stool after 24 hours & No & 301 & 82.9 \\
\hline
\end{tabular}




\begin{tabular}{|llll|}
\hline Kknowinustules & & Frequency & Percent \\
\hline Yes & 62 & 17.1 \\
No & 231 & 63.6 \\
\hline & Yes & 132 & 36.4 \\
\hline
\end{tabular}

\section{Factors associated with maternal knowledge about neonatal danger signs.}

After controlling economic, family size, mothers' occupation, husband's occupation, religion and financial preparation: Maternal age, mothers' educational status, mode of delivery, parity, PNC visit, identification of skilled birth attendant, information from health professionals, health extension workers and television as well as education during PNC follow up were the factors that significantly associated with maternal knowledge. Mothers whose age 25-34 were 2.99 times (AOR $=2.99,95 \% \mathrm{Cl}: 1.18-7.54$ ) and 35 - 44 were 4.97 times (AOR=4.97, 95\% Cl: 1.65-18.02) more knowledgeable as compared to mothers who were younger than these age groups. Similarly, mothers who had more than three parity were 5.34 times (AOR=5.34, 95\% Cl: 1.64-2.64) more likely to be knowledgeable as compared to their counterpart. Participants who had three and more than three PNC visit during the last delivery (AOR=3.72, 95\% $\mathrm{Cl}$ : 1.92-7.21) were 3.72 times more likely to be knowledgeable on neonatal danger signs.

Furthermore, mothers who had birth preparedness on identification of skilled birth attendant during pregnancy had 2.25 times (AOR= 2.25, 95\% $\mathrm{Cl}: 1.13$ - 4.40) more knowledge on neonatal danger signs as compared to their counterpart. In addition to this, mothers who had source of information from health professionals ( $\mathrm{AOR}=4.54,95 \% \mathrm{Cl}: 2.16-9.70$ ) were 4.54 times more likely to be knowledgeable as compared to their counterpart. Likewise, participants who had education about neonatal danger signs during PNC visit were 2.77 times ( $A O R=2.77(1.49-5.15)$ more knowledgeable to identify neonatal danger sign as compared to those mothers who had no education during PNC visit (Table 5). 
Table 5

Bivariable and multivariable analysis showing factors associated with maternal knowledge on neonatal danger signs among post natal mothers at Gandhi, Black lion and St. Peter hospitals from March 15th May 15th, $2019(\mathrm{~N}=363)$.

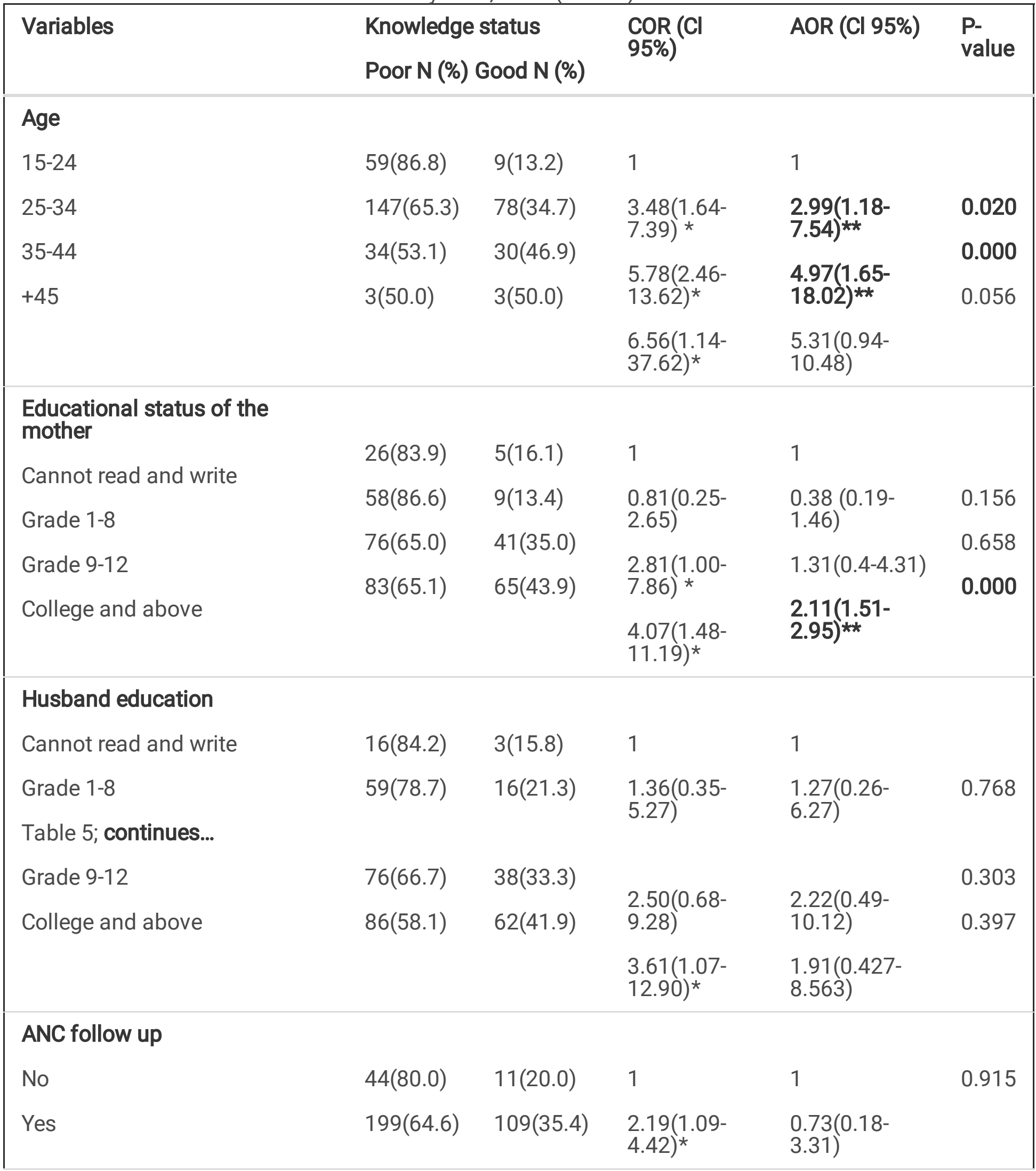

* = Association at $P$-value $<0.2$ in bivariable logistic regression and ** = Statisttically significant association at $P$ - value $<0.05$ in multivariable logistic regration. 


\begin{tabular}{|c|c|c|c|c|c|}
\hline \multirow[t]{2}{*}{ Variables } & \multirow{2}{*}{\multicolumn{2}{|c|}{$\begin{array}{l}\text { Knowledge status } \\
\text { Poor N (\%) Good N (\%) }\end{array}$}} & \multirow{2}{*}{$\begin{array}{l}\text { COR (Cl } \\
95 \%)\end{array}$} & \multirow[t]{2}{*}{ AOR (Cl 95\%) } & \multirow{2}{*}{$\begin{array}{l}\mathrm{P} \text { - } \\
\text { value }\end{array}$} \\
\hline & & & & & \\
\hline \multicolumn{6}{|l|}{ Place of delivery } \\
\hline Health center & $50(75.8)$ & $16(24.2 \%)$ & 1 & 1 & 0.535 \\
\hline Hospital & $171(62.4)$ & 103(37.6) & $1.88(1.02-$ & $1.31(0.56-$ & 0.165 \\
\hline Home & $22(95.8)$ & $1(4.3)$ & $\begin{array}{l}0.14(0.02- \\
1.14)\end{array}$ & $\begin{array}{l}0.18(0.02- \\
2.01)\end{array}$ & \\
\hline \multicolumn{6}{|l|}{ Mode of delivery } \\
\hline Spontaneous delivery & $85(75.2)$ & $28(24.8)$ & 1 & 1 & \\
\hline Instrumental delivery & $32(60.4)$ & 21(39.6) & $\begin{array}{l}1.99(0.99- \\
3.99)\end{array}$ & $\begin{array}{l}1.63(0.61- \\
4.34)\end{array}$ & 0.331 \\
\hline Caesarean section & $126(64.0)$ & $71(36.0)$ & $\begin{array}{l}2.71(1.02- \\
2.87) *\end{array}$ & $\begin{array}{l}3.72(1.71- \\
8.12) \star \star\end{array}$ & 0.001 \\
\hline \multicolumn{6}{|l|}{ Parity } \\
\hline 1 & $39(86.7)$ & $6(13.3)$ & 1 & 1 & \\
\hline $2-3$ & $129(84.4)$ & $24(15.7)$ & $\begin{array}{l}1.21(0.46- \\
317)\end{array}$ & $\begin{array}{l}1.11(0.40- \\
4.08)\end{array}$ & 0.682 \\
\hline$>3$ & $75(45.5)$ & $90(54.5)$ & 7801212 & 5340164 & 0.005 \\
\hline Frequency of PNC & & & $19.43)^{\star}$ & $2.64)^{\star *}$ & \\
\hline$<3$ & $114(75.0)$ & $38(25.0)$ & & & \\
\hline$\geq 3$ & $99(60.0)$ & $66(40.0)$ & 1 & 1 & 0.000 \\
\hline & & & $\begin{array}{l}2.00(1.24- \\
3.24) *\end{array}$ & $\begin{array}{l}3.72(1.92- \\
7.21) \star \star\end{array}$ & \\
\hline \multicolumn{6}{|c|}{$\begin{array}{l}\text { Identification of skilled birth } \\
\text { attendant }\end{array}$} \\
\hline No & 130(79.3) & $34(20.7)$ & 1 & 1 & \\
\hline Yes & $113(56.8)$ & $86(43.2)$ & $\begin{array}{l}2.91(1.82- \\
4.66)^{\star}\end{array}$ & $\begin{array}{l}2.25(1.13- \\
4.40)^{\star \star}\end{array}$ & 0.022 \\
\hline \multicolumn{6}{|l|}{$\begin{array}{l}\text { Information from health } \\
\text { professional }\end{array}$} \\
\hline Yes & $147(58.1)$ & $106(41.9)$ & $\begin{array}{l}4.95(2.68- \\
9.14)^{\star}\end{array}$ & $\begin{array}{l}4.54(2.16- \\
9.70) \star \star\end{array}$ & 0.000 \\
\hline
\end{tabular}

* = Association at $P$-value $<0.2$ in bivariable logistic regression and ** = Statisttically significant association at $P$-value $<0.05$ in multivariable logistic regration. 


\begin{tabular}{|c|c|c|c|c|c|}
\hline \multirow[t]{2}{*}{ Variables } & \multicolumn{2}{|c|}{ Knowledge status } & \multirow{2}{*}{$\begin{array}{l}\mathrm{COR}(\mathrm{Cl} \\
95 \%)\end{array}$} & \multirow[t]{2}{*}{ AOR (Cl 95\%) } & \multirow{2}{*}{$\begin{array}{l}\mathrm{P} \text { - } \\
\text { value }\end{array}$} \\
\hline & Poor N (\%) & Sood N (\%) & & & \\
\hline \multicolumn{6}{|c|}{ Health extension workers } \\
\hline No & 169(79.7) & $43(20.3)$ & 1 & 1 & \\
\hline Yes & $74(49.0)$ & $77(51.0)$ & $\begin{array}{l}4.09(2.56- \\
6.49) *\end{array}$ & $\begin{array}{l}2.67(1.54- \\
4.62) * *\end{array}$ & 0.000 \\
\hline \multicolumn{6}{|l|}{ Television } \\
\hline No & 129(83.8) & $25(16.2)$ & 1 & 1 & \\
\hline Yes & $114(54.5)$ & $95(45.5)$ & $\begin{array}{l}3.00(2.59- \\
7.14)^{\star}\end{array}$ & $\begin{array}{l}2.15(1.11- \\
4.15)^{\star *}\end{array}$ & 0.023 \\
\hline \multicolumn{6}{|c|}{$\begin{array}{l}\text { Education during PNC follow } \\
\text { up }\end{array}$} \\
\hline No & $92(48.2)$ & $99(51.8)$ & 1 & 1 & 0.001 \\
\hline Yes & & & $\begin{array}{l}7.74(4.52- \\
13.25)^{\star}\end{array}$ & $\begin{array}{l}2.77(1.49- \\
5.15) * \star\end{array}$ & \\
\hline
\end{tabular}

\section{Discussion}

Maternal knowledge on neonatal danger signs is the major contributing factor for the reduction of neonatal morbidity and mortality which requires a compressive health care [24]. Because reducing neonatal morbidity and mortality requires immediate caregiver's knowledge on common neonatal danger signs and visiting the nearby health facility. According to this study, the prevalence of maternal good knowledge on neonatal danger signs was $33.1 \%$. This is lower than the study conducted in Nepal which was 35.63\% [25], Port Harcourt Nigeria which was 45.2\% [26] and the study done in Bangladesh 50\% [27] but higher than the study done in Nigeria, Sudan, Kenya and Gahana which were 30.3\%, 20.4\%, $15.5 \%$ and $28.1 \%[28,29,30,31]$ respectively.

This study good knowledge level is also higher than the study done in Woldia general hospital which was $11.67 \%$ [32]. The discrepancy might be due to time difference in assessing maternal knowledge (previous studies assessed maternal knowledge after neonatal period which were exposed to recall bias), difference in study setting, time gap, sample size variation, difference in knowledge assessment questions and evaluation method. In addition to this, the possible explanation might be due to participant place of residence, difference in health care delivery system or difference in intervention program, difference in access to media and educational difference or information gap about neonatal danger signs. This study also reported that, majority of the mothers (72.5\%) knew fever as common neonatal danger sign which is supported by Nigerian [28] and Kenyan studies [30]. The possible justification for 
this might be this symptom is easily felt by mothers when they touch their neonates and it is an alarming sign for systemic infection and easily detected by mothers.

This study also showed that mothers' age was statistically significant factor to maternal knowledge on neonatal danger signs. Mothers who were 25-34 and 35-44 years old had nearly three and four times respectively knowledgeable as compared to mothers who were less than 15-24 years old. This is supported by the studies done in Bangladesh [27] and Woldia [32]. This might be due to in this age group mothers have experience on symptoms that occur on neonates and children. In addition to this, they are active reproductive age group and child-bearing age women; they can give attention to neonates. But this study finding is incongruent with the study done in Nigeria, Sudan and Kenya [29, 31, 32]. The possible justification for this difference might be due to the case that health care providers deliver health information or counseling about neonatal danger signs regardless of age differently in different areas.

Likewise, educational status of the mothers was statistically significant to maternal knowledge. Those mothers who had college and above educational status were two times more knowledgeable as compared to who cannot read and write. This is consistent with the study done in Gondar, Woldia and Bangladesh [24, 27, 32]. The possible justification for this could be educated mothers were more likely to made decision to look for quality health service, had better access to health service information, took their sick neonate to health institution and get additional information about neonatal danger signs and improved knowledge on neonatal danger signs. Moreover, they acquire knowledge on disease and neonatal conditions as well as child health through their academic life. But this is incongruent with the study done in Rural Uganda [7]. The difference might be due to information gap and difference in accessibility of media. Similarly, those mothers who delivered by caesarean section were nearly four times more likely to be knowledgeable as compared to mothers who had spontaneous vaginal delivery. This is supported by the study done in Bangladesh [27]. The possible explanation for this might be mothers who delivered by cesarean section had more health professional contact and long hospital stay; this in turn creates an opportunity to get education about neonatal danger signs from health care providers.

Moreover, PNC visit for the last child and parity were significantly associated with maternal level of knowledge. Mothers who had three and above PNC visit were nearly four times and participants who had more than three parity had five times more likely to be knowledgeable as compared to those who had less than three PNC follow up and less than five parity. This is supported by the study conducted in Gondar [24]. The justifiable reason for this might be education during PNC visit and also may be those mothers who have high parity were exposed to neonatal danger signs knowledge at some point during their previous ANC and PNC visit and have their own experiences of neonatal danger signs from previous delivery. However, the finding of this study is in part different from the study done in Chencha [23].This discrepancy might be due to the fact that educational difference during PNC visit, difference in study setting and difference in maternal exposure to neonatal danger signs from previous delivery. 
According to this study report, birth preparedness was statistically significant to mothers' knowledge on neonatal danger signs. Participants who identified skilled birth attendant for the last delivery had two times more knowledge about neonatal danger signs as compared to who had no birth preparedness which is consistent with the study done in Uganda [9]. The possible reason for this might be due to getting information about neonatal danger signs from birth attendants. Because identifying birth attendants increase contact of mothers with knowledgeable personnel and create a good opportunity to get the necessary information about neonates and young infant illness.

Source of information about neonatal danger signs was statistically significant to mothers' knowledge. This finding is supported by the study conducted in India [33], Chencha [23] and Gondar [24]. Mothers who got information from health professionals were 4.54 times more likely to be knowledgeable about neonatal danger signs as compared to those who did not get information. The possible explanation for this might be mothers who give birth in health institution and who had PNC follow up receives post natal counseling by health professionals on appropriate time; this increases their knowledge and they pied attention what they told. This study also showed that, mothers who had television access had two times more knowledge than their counterpart. This is supported by the study done in Gondar [24]. The possible justification for this could be television contains a segment of airtime dedicated to teach the mother about health issue of neonates and children. Therefore, using television could also increase the memorability of the message compared to other Medias and the similarity of these two studies might be due to similar accessibility of television to mothers.

Moreover, education during PNC visit was statistically significant to maternal knowledge on neonatal danger signs. Mothers who got education during PNC visit were nearly three times more likely to be knowledgeable as compared to their counterpart. The possible explanation for this could be getting education creates awareness and make mothers more conscious for neonates' infection indicator signs and alert to every symptom. This is also initiate mothers to take their neonates to health institution and help to get additional information.

Including NICU in the study area makes important to assess maternal knowledge on neonatal danger signs since this area is the most critical area those neonates who had danger signs were found. Collecting data within 28 days of delivery minimize recall bias and helps to identify the true maternal knowledge and data collectors were trained health professionals that contribute the quality of the data. Moreover, this study includes more than one study area (multicenter study) which increase external validity of the study and used relatively large sample size. Despite the above strength, its cross-sectional nature of the study affects the establishment of the cause and effect relationship between maternal knowledge on neonatal danger signs and the factors that were identified.

\section{Conclusion}

The finding of this study revealed that, the prevalence of maternal knowledge regarding to neonatal danger signs was poor which is only $33.1 \%$ of mothers had good knowledge. This study also identified 
that maternal age, maternal education, mode of delivery, parity, birth preparedness, and three and above three PNC visit, source of information about neonatal danger signs from health professionals and television and education during PNC visit were statistically significant factors to maternal knowledge on neonatal danger signs.

\section{List Of Abbreviations}

ANC, antenatal care; AOR, adjusted odds ratio; $\mathrm{BSc}$, bachelor of Science; $\mathrm{Cl}$, confidence interval; CSAE, central statistical agency of Ethiopia; IMNCl, integrated management of newborn and childhood illness; IRB, institutional review board; NICU, neonatal intensive care unit; PNC, postnatal care; SD, standard deviation; SPSS, statistical package for social sciences; TASH, Tikure Anbessa specialized hospital; WHO, world health organization.

\section{Declarations}

\section{Ethical approval and consent to participate}

Ethical clearance and ethical approval were obtained from the Intuitional Review Board (IRB) of Addis Ababa University. After ethical clearance obtained, supportive letter was received from department of nursing and midwifery to the study hospitals. Permission letters were obtained from each hospital administration. Informed consent was obtained from each participant (mother or attendant of new born) after explaining the purpose and benefits of the study and their participation was on voluntary basis. All information was kept confidential and no individual identifiers were collected.

\section{Consent for publication}

Not applicable yet.

\section{Availability of data and materials}

Extra data that support the findings of this study are available from the corresponding author upon reasonable request via wudieeneyew01@gmail.com

\section{Competing interests}

The authors declared that they have no conflict of interests.

\section{Funding}

This research received no specific grant from any funding agency in the public, commercial, or not-forprofit sectors. However, St Peter Specialized Hospital provided the financial backing of this research. The funder had no role in the study design, data collection, analysis, preparation of the manuscript, and decision to publish. 


\section{Authors' contributions}

WEA, ABW, AB \& GWT participated in the study conception, data collection and interpretation of the data. WEA \& ABW participated in the design, performed the statistical analysis, as well as drafted and critically revised the manuscript. WEA edited the manuscript and formatted it for publication. All authors read and approved the final manuscript and agreed to be accountable for all aspects of the work. RM \& TT advised during proposal development, edited the proposal, and advised during data analysis

\section{Acknowledgment}

We would like to thank Addis Ababa University that offered the chance and sponsored this study. Authors gratefully thank goes to data collectors, supervisors and respective hospitals coordinators who involved in the study for their wholehearted contributions.

\section{References}

1. Baqui AH, Rahman M, Zaman K, El Arifeen S, Chowdhury HR, Begum N, et al. A population-based study of hospital admission incidence rate and bacterial aetiology of acute lower respiratory infections in children aged less than five years in Bangladesh. J Heal Popul Nutr. 2013;25(2):179188.

2. Dominic A, Joy A, P.S A, Kurian A, Jose A, G.S .Shilpa. Knowledge on Warning Signs of New Born Illness Among the Mothers With a View To Develop an Information Booklet in India. Am Int J Res Humanit Arts Soc Sci. 2013;4(1):92-94.

3. Oza S, Cousens SN, Lawn JE. Estimation of daily risk of neonatal death, including the day of birth, in 186 countries in 2013: A vital-registration and modelling-based study. Lancet Glob Heal [Internet]. 2014;2(11):e635-e644. http://dx.doi.org/10.1016/S2214-109X(14). Available from: http://dx.doi.org/10.1016/S2214-109X(14)70309-2.

4. Identifying and managing clinical risks in newborn babies and providing care for infants in the community who need respiratory support.Commission care quality. 2016.

5. Sibley LM, Tesfaye S, Desta BF, Hailemichael A, Kebede A, Mohammed H, et al. Improving Maternal and Newborn Health Care Delivery in Rural Amhara and Oromiya Regions of Ethiopia Through the Maternal and Newborn Health in Ethiopia Partnership. lournal midwifery womenes Heal. 2015;59(1):1-20.

6. Li Liu, Shefali Oza, Dan Hogan, Yue Chu, Jamie Perin, Jun Zhu, Joy E Lawn, Simon Cousens, Colin Mathers REB. Global, regional, and national causes of under-5 mortality in 2000-15: an updated systematic analysis with implications for the Sustainable Development Goals. Bill Melinda Gates Found WHO. 2016;388(3027-35):3027-3035. DOi.http://dx.doi.org/10.1016.

7. Sandberg J, Pettersson KO, Asp G, Kabakyenga J, Agardh A. Inadequate Knowledge of Neonatal Danger Signs among Recently Delivered Women in Southwestern Rural Uganda: A Community Survey. PLOS ONE | www.plosone.org. 2014;9(5):5 | e97253.DOI.10.1371/journal.pone.0097253. 
8. Unicef. Newborn Health FIELD GUIDE in umanitarian Setting in India. United Nations Children's Fund and Save the Children. 2015.

9. UNICEF. Child mortality. 2019.

10. Okawa S, Ansah EK, Nanishi K, Enuameh Y. High Incidence of Neonatal Danger Signs and Its Implications for Postnatal Care in Ghana: A Cross-Sectional Study. Neonatal Morb Its Implic Postnatal Care Ghana. 2015;10(6):1-13. DOI:10.1371/journal.pone.0130712

11. WHO/UNICEF. Integrated Management of Newborn and Childhood Illness, Part 1. Federal Democratic Republic of Ethiopia Ministry of Health Integrated. 2015. 1-126. Health Education and Training) website at $\mathrm{w} p$.

12. Save the children. Facilitated Referral for Newborns with Danger Signs: The role of community health workers. 2013.

13. Neonatal Intensive Care Unit (NICU) Training Management Protocol. Addis Ababa. Federal Ministry of Health of Ethiopia. 2014. 1-224 p.

14. Darmstadt GL, Oot DA, Lawn JE. Newborn survival: changing the trajectory over the next decade. Health Policy Plan. 2012;27:1-5.doi:10.1093/heapol/czs054.

15. Waiswa P, Kallander K, Peterson S, Tomson G, Pariyo GW. Using the three delays model to understand why newborn babies die in eastern Uganda. Trop Med Int Heal. 2010;15(8):964-972. doi:10.1111/j.1365-3156.2010.02557.

16. Central Statistical Agency (CSA) [Ethiopia] and ICF. 2016. Ethiopia Demographic and Health Survey 2016. Addis Ababa, Ethiopia, and Rockville, Maryland, USA: CSA and ICF.

17. Thakur R, Sharma RK, Kumar L, Pugazhendi S. Neonatal Danger Signs: Attitude and Practice of PostNatal Mothers in India. J Nurs Care. 2017;6(3):1-5. DOI: 10.4172/2167-1168.1000401.

18. Yadeta TA. Antenatal care utilization increase the odds of women knowledge on neonatal danger sign: a community - based study, eastern Ethiopia. BMC Res Notes [Internet]. 2018;11(845):1-5.

19. Melkamu B, Berhane M, Yimam H, Jibat N, Zewdu M. Parents ' Knowledge of Danger Signs and Health Seeking Behavior in Newborn and Young Infant Illness in Tiro Afeta District, Southwest Ethiopia :A Community-based Study. Ethiop J Heal Sci. 2018;28(4):473-481.DOI: http://dx.doi.org/10.4314/ejhs.v28i4.

20. Assefa N, , Yihune Lakew, Betelhem Belay, Haji Kedir, Desalew Zelalem, Negga Baraki, Melake Damena, Lemessa Oljira WA and MD. Neonatal mortality and causes of death in Kersa Health and Demographic Surveillance System (Kersa HDSS), Ethiopia, 2008-2013.Haramaya University. Matern Heal Neonatol Perinatol. 2016;2(7):1-10. DOI 10.1186/s40748-016-0035-8.

21. Central Statistical Agency of Ethiopia (CSAE)survey.Population Census Commission. Addis Abab; 2007.

22. Walellign Anmut BF and TD. Mother's knowledge and Practice about Neonatal Danger Signs and Associated Factors in Wolkite Town, Gurage Zone, SNNPR, Ethiopia, 2017. J Biomed Sci ISSN. 2017;6(5:33):1-7.DOI: 10.4172/2254-609X.100077 
23. Mersha A, Assefa N, Teji K, Bante A, Shibiru S. Mother's Level of Knowledge on Neonatal Danger Signs and Its Predictors in Chencha District, Southern Ethiopia. Am J Nurs Sci. 2017;6(5):426-432. http://www.sciencepublishinggroup.com/j/a.

24. Nigatu SG, Worku AG, Dadi AF. Level of mother's knowledge about neonatal danger signs and associated factors in North West of Ethiopia: a community based study in University of Gondar 32. BMC Res Notes. 2015;8(309):1-6.

25. Shrestha T, Bhattarai SG, Silwal K. Knowledge and Practice of Postnatal Mother in Newborn Care in Nepal. Orig Artic J Nepal Med Assoc. 2013;52(190):7-372.

26. Balafama Alex-Hart PO. Mothers ' recognition of newborn danger signs and health seeking behaviour.University of Port Harcourt Nlgeria. Niger J Paediatr Paed. 2017;41(3):199 -203.

27. Zaman S Bin, Hossain N, Hussain MA, Abimanue V. Factors related to knoledge on neonatal danger signs among the recently deliveredwomen in sub- district hospitals of Bangladish.PublicHeal. 2017;3(2):50-60.

28. Ekwochi U, Ndu IK, Osuorah CDI, Amadi OF, Okeke IB, Obuoha E, et al. Knowledge of danger signs in newborns and health seeking practices of mothers in Enugu state, South-East Nigeria. Ital J Pediatr. 2015;41(18):1-7. DOI 10.1186/s13052-015-0127-5.

29. Sami S, Kerber K, Kenyi S, Amsalu R, Tomczyk B, Jackson D, et al. State of newborn care in South Sudan's displacement camps: a descriptive study of facility-based deliveries. Sami alReproductive Heal. 2017;14(161):1-12.DOI 10.1186/s12978-017-0417-z.

30. Kibaru EG, Otara AM. Knowledge of neonatal danger signs among mothers attending well baby clinic in Nakuru Central District, Kenya: cross sectional descriptive study. BMC Res Notes. 2016;9(481):18.DOI 10.1186/s13104-016-2272-3.

31. Kuganab-lem R, Yidana A. Exploring Women Knowledge of Newborn Danger Signs: A Case of Mothers with under Five Children in Tamale, Ghana. Public Heal Res. 2014;4(5):195-202.DOI: 10.5923/j.phr.20140405.07.

32. Jemberia MM, Berhe ET, Mirkena HB, Gishen DM, Tegegne AE, Reta MA. Low level of knowledge about neonatal danger signs and its associated factors among postnatal mothers attending at Woldia general hospital , Ethiopia. Matern Heal Neonatol Perinatol. 2018;4(5):1-8.DOI 10.1186/s40748-018-0073-5.

33. Girijamma S, Padmaja A. Descriptive study to assess the knowledge on warning signs of selected newborn illness among the primimothers with a view to develop an information booklet in India. Int $J$ Appl ied Res. 2017;3(9):518-521.

\section{Figures}




\section{Source of information on neonatal danger signs}

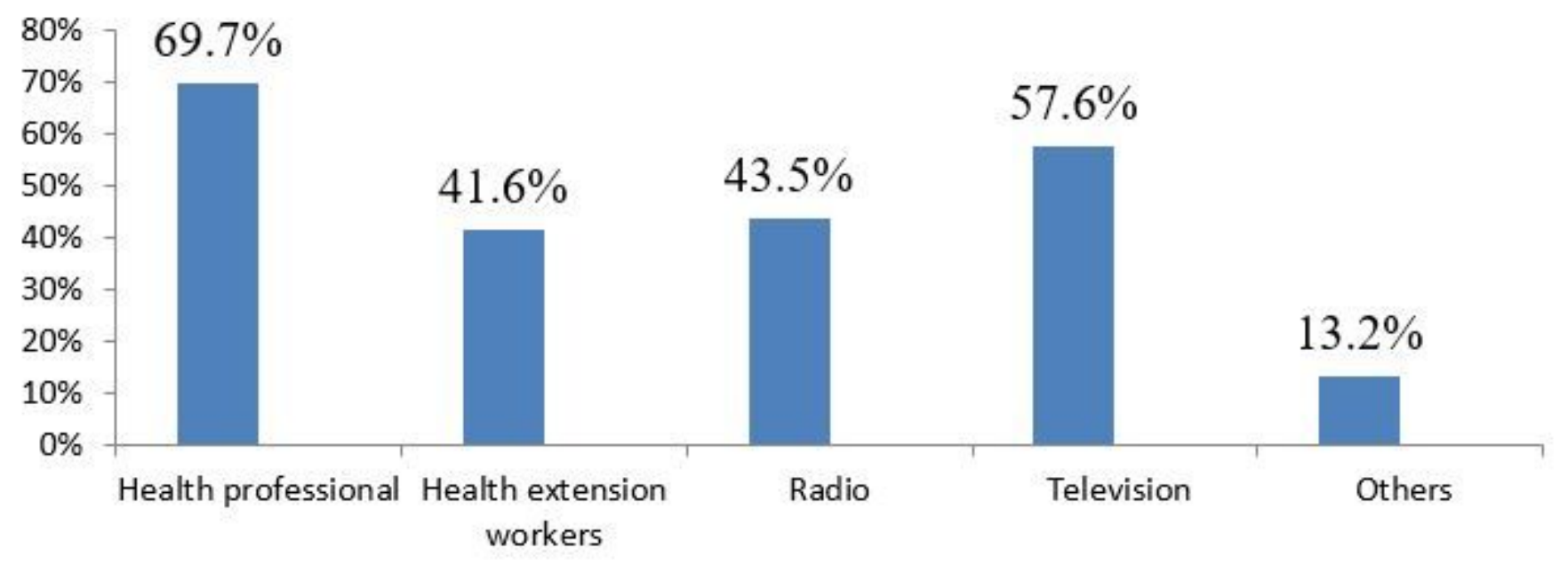

Figure 1

source of information on neonatal danger signs among post natal mothers.

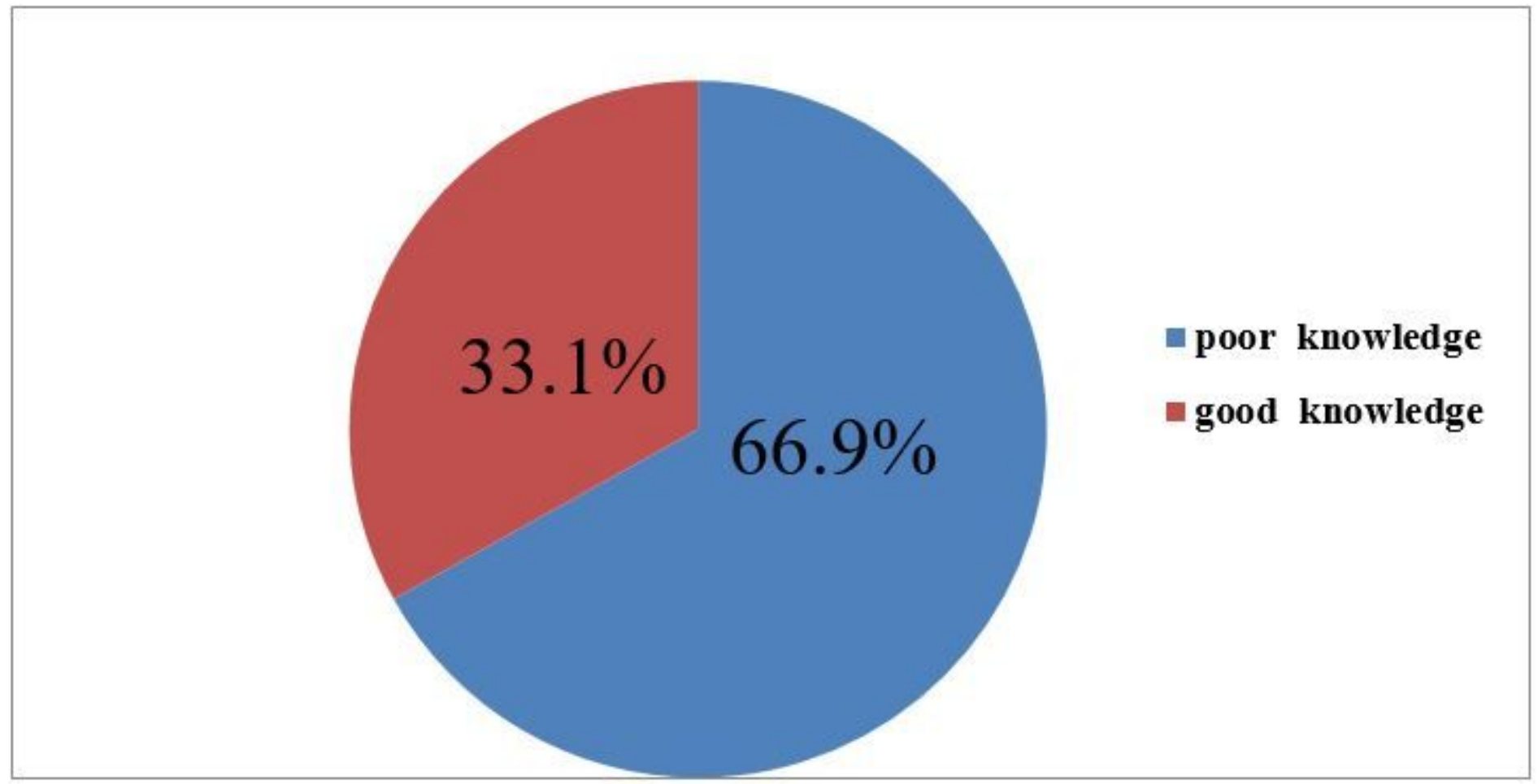

Figure 2

Maternal knowledge status on neonatal danger signs among post natal mothers 